\title{
A New Semi-airborne Transient Electromagnetic System and Application of Detecting Underground Conductor in East Ujimqin Banner, China
}

\author{
Fubo Liu*, Ling Huang, Liu Lihua, Jutao Li, Zhi Geng, Qimao Zhang, Guangyou Fang \\ Key Laboratory of Electromagnetic Radiation and Sensing Technology, Chinese Academy of Sciences, China
}

\begin{abstract}
Airborne electromagnetic method (AEM) as an efficient, regional geophysical electromagnetic method has been widely used in geological survey, mineral exploration, environmental monitoring and other fields, but not in China for the civil aviation law and the safety consideration. We introduce a new semi-airborne transient electromagnetic (S-ATEM) system based on the unmanned aerial vehicle (UAV), and use a grounded electrical wire source which can provide a larger moment compare to the traditional AEM. We have taken an survey in East Ujimqin Banner, north east of China and the survey result indicates that the S-ATEM system has a greater investigation depth compared to the ground TEM system, and with more efficient, low cost, and safety.
\end{abstract}

Keywords—s-atem system; UAV; induction magnetic sensor; field survey

\section{INTRODUCTION}

Airborne electromagnetic method originated in the fifties and sixties of the last century, it is an efficient, regional geophysical electromagnetic method. Helicopter or fixed-wing aircraft is used as the flying platform in traditional airborne electromagnetic system. The transmitting system and the receiving system are both mounted on the flying platform. The mobility of the flying platform makes it very suitable for large area exploration. But there are two major issues limiting the application of the airborne electromagnetic method. Firstly, the limitation of magnetic moment generated by magnetic source mounted on the flying platform. Secondly, the small transmitter-receiver distance couldn't get a considerable investigation depth.

Semi-airborne transient electromagnetic system is a hybrid ground-air system that combines the use of a large ground wire or loop transmitter with an airborne receiver. The purpose of the semi-airborne transient electromagnetic system is to improve the investigation depth of airborne electromagnetic system. Elliott developed a fixed loop airborne transient electromagnetic (FLAIRTEM) system ${ }^{[1]}$, which uses magnetic source. The side length of the transmitter loop is usually several kilometers, and had make many testing surveys in Australia and Papua New Guinea over a number of mineral deposits ${ }^{[2]}$. Mogi et al. from Japan developed a new airborne EM system named grounded electrical source airborne transient electromagnetic (GREATEM) system ${ }^{[3]}$. The GREATEM can obtain a greater depth of investigation using a grounded wire source and a long transmitter-receiver distance. Then they use the GREATEM for the volcanic structure $^{[4,8]}$, the coastal zone underground structure ${ }^{[5,7]}$, and the tunnel investigation ${ }^{[6]}$. Previous studies show that GREATEM can be used in both resistive and conductive area. The investigation depth of GREATEM can be up to $800 \mathrm{~m}$ at resistive area and more than $300 \mathrm{~m}$ at a conductive area. Richard Smith et al. makes a comparison of survey data from airborne (GEOTEM), semi-airborne (TerraAir), and ground (PROTEM) electromagnetic systems ${ }^{[9]}$. It shows that semiairborne EM system has a greater investigation depth compared with traditional airborne EM system, and has a lower cost compared with ground based TEM systems.

We introduce a new semi-airborne transient electromagnetic (S-ATEM) system in this paper. The SATEM system uses a grounded electrical wire source more than $2 \mathrm{~km}$ length and a three-component induction coil which mounted on a towed bird. The bird is towed under the unmanned aerial vehicle (UAV), a high-precision inertial navigation system (INS) is also mounted on the bird, which can monitor and log the coordinates and attitude of the EM sensors. The S-ATEM can be widely used in geological survey, mineral exploration, environmental monitoring, and other fields due to the small size, light weight, low cost, easy implementation, and safety comparing to the traditional airborne EM systems.

\section{Methodology}

\section{A. S-ATEM System}

Fig.1 shows an overview of the S-ATEM system, includes transmitter unit, receiver unit, aerial platform unit, and data processing unit, the specification of S-ATEM is showed in TABLE I.

The transmitter unit consists of power generator, square pulse transmitter, several kilometers cable and grounded electrodes. The outputted bipolar square current pulse with specific frequency can radiate electromagnetic signal into the ground by the transmitting wire. The max output voltage is $1000 \mathrm{~V}$, and the max output current is $40 \mathrm{~A}$. The duty cycle of the transmitter can be adjusted from 0 to $100 \%$, and the repeated frequency can be selected from $10 \mathrm{kHz}$ to $15 \mathrm{~s}$ according to the expected survey depth.

The receiver unit includes a multi-channel receiver, threecomponent induction magnetic sensor and INS. Multi-channel 
receiver is installed under the bottom of the UAV. The magnetic sensor and INS are towed in the bird suspended beneath the UAV with a distance of about $25 \mathrm{~m}$. The receiver has six 24 bit, 48ksps ADCs to record the electromagnetic signals of three orthogonal components, and sets different channel gain from 256 to $1 / 4$ for data recording. A new orthogonal three-component induction magnetic sensor is designed for the S-ATEM system, with the characteristic of larger effective area, higher resonant frequency and lower noise for a greater depth investigation.

The dynamic attitude measurement accuracy of INS is 0.1 degree, even the attitude accuracy can reach 0.05 degree when do the differential calculation with the base station data on the ground. An UAV with payload more than $80 \mathrm{~kg}$ is chosen for the consideration of system weight and safety.
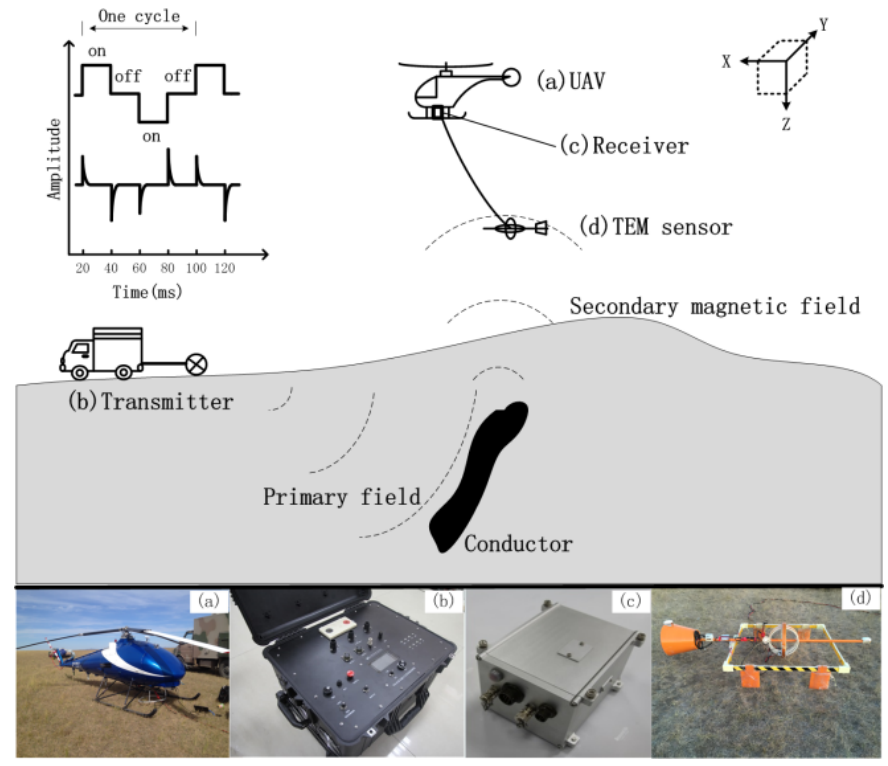

Fig. 1. Overview of S-ATEM system (a) UAV platform (b) Transmitter (c) Multi-component receiver (d) Towed bird. Towed bird contained the three-component induction magnetic sensor and INS.

\section{B. Data Processing}

Data processing has four main parts and the flow chart is show in Fig.2.

\section{a) Motion-induced noise correction}

Motion-induced noise is removed by the ensemble empirical mode decomposition (EEMD) method. It decompose the EM signal into $\mathrm{N}$ order intrinsic mode functions (IMFs) and residual function, and rejects the IMFs of low frequency component which is considered to be the motion-induced noise. After reconstruction, a motion noise free EM signal can be obtained.

\section{b) Attitude correction}

The attitude and coordinate data is collected for attitude correction and inversion using INS unit and GPS logger. Attitude data includes yaw, pitch, and roll representing angles of the bird. A rotation matrix for attitude correction of the raw EM data makes the attitude correction simply. The matrix $\mathrm{R}$ is three by three with the variety of $\delta_{\mathrm{Y}}, \delta_{\mathrm{P}}$ and $\delta_{\mathrm{R}}$ representing yaw, pitch, and roll of the bird respectively. The corrected data is calculated by the formula $\mathrm{H}=\mathrm{RH}$, where $\mathrm{H}$ is the raw survey data and $\mathrm{H}^{\prime}$ is the corrected data.

TABLE I. SPECIFICATIONS OF S-ATEM SYSTEM

\begin{tabular}{|c|c|}
\hline \multicolumn{2}{|c|}{ Specification of Transmitter } \\
\hline Input power & AC $50 / 60 \mathrm{~Hz} 380 \mathrm{~V}, 50 \mathrm{~kW}$ \\
\hline Output waveform & Bipolar square wave \\
\hline Base frequency & $15 \mathrm{~s} \sim 10 \mathrm{kHz}$ \\
\hline Current duty & $0 \sim 100 \%$ \\
\hline Output current & $1 \mathrm{~A} \sim 40 \mathrm{~A}$ \\
\hline Output voltage & $20 \mathrm{~V} \sim 1000 \mathrm{~V}$ \\
\hline Maximum power & $20 \mathrm{~kW}$ \\
\hline Synchronization & $\mathrm{GPS}+\mathrm{OCXO}$ \\
\hline Synchronization accuracy & $100 \mathrm{~ns}$ \\
\hline Current waveform digital record & $\begin{array}{l}\text { Yes, } 48 \mathrm{kSPS}, 24 \mathrm{bit} \\
0.5 \mathrm{~A} \text { resolution }\end{array}$ \\
\hline \multicolumn{2}{|c|}{ Specification of Multi-channel Receiver } \\
\hline Observing field & $\mathrm{X}, \mathrm{Y}, \mathrm{Z}$ \\
\hline ADC Channels & 6 \\
\hline Signal gain & $0.25,1,4,16,32,64,128,256$ \\
\hline Sampling rate & $48 \mathrm{kSPS}$ \\
\hline Input signal range & $-10 \mathrm{~V} \sim 10 \mathrm{~V}$ \\
\hline ADC bit width & $24 \mathrm{bit}$ \\
\hline Dynamic range & $160 \mathrm{~dB}$ \\
\hline Synchronization & $\mathrm{GPS}+\mathrm{OCXO}$ \\
\hline Control interface & RS232, RS485 \\
\hline Attitude monitoring and accuracy & Three-axis, \pm 0.05 degree \\
\hline Position accuracy & $\begin{array}{l}\text { Centimeter after differential } \\
\text { processing }\end{array}$ \\
\hline Controller and processer & $\mathrm{ARM}+\mathrm{DSP}$ \\
\hline Control mode & WIFI and digital radio \\
\hline Storage capacity & $32 \mathrm{~GB}$ \\
\hline Power consumption & $8 \mathrm{~W}$ \\
\hline Weight(with battery) & $3.2 \mathrm{~kg}$ \\
\hline \multicolumn{2}{|c|}{ Specification of Induction Magnetic Sensor } \\
\hline Effective area $\left(\mathrm{m}^{2}\right)$ & $X(5700) Y(5800) Z(24000)$ \\
\hline Resonant frequency $(\mathrm{kHz})$ & $X(29.7) Y(23.5) Z(9.7)$ \\
\hline Noise level & $\begin{array}{l}1 \mathrm{mV} @ 20 \mathrm{kHz}(18 \mathrm{nT} / \mathrm{s}) \\
83 \mathrm{uV} @ 1 \mathrm{kHz}(1.4 \mathrm{nT} / \mathrm{s})\end{array}$ \\
\hline Bird weight & $18.7 \mathrm{~kg}$ \\
\hline
\end{tabular}




\section{c) Stacking and filtering}

Data stacking and filtering is used to minimize the random noise and cultural noise. The speed of UAV is about $15 \mathrm{~m} / \mathrm{s}$, and the repeated base frequency is $12.5 \mathrm{~Hz}$, we can get the lateral resolution up to $30 \mathrm{~m}$ and stack cycle signal up to 50 times when taking time interval of $2 \mathrm{~s}$. It may be more effective to use $4 \mathrm{~s}$ interval or overlap $50 \%$ of each neighbor interval in noisy environment. A median filter is also used to smoothing the decay after we got the transient curve.

\section{d) One-dimension model inversion}

One dimension occam's inversion based on smooth model is used for the inversion of the field data underground, and we can get the structure subsurface by comparing the field curve to the theoretical curve.

\section{APPLICATION AND RESULT}

The survey site is located in the East Ujimqin Banner, north east of China, which is belonged to the middle east Inner Mongolia Plateau with an average altitude of about $913 \mathrm{~m}$. The survey area is about eight square kilometers, we had designed 11 flight lines spaced $200 \mathrm{~m}$, and each line has a length of $5 \mathrm{~km}$. A $2.2 \mathrm{~km}$ long transmitter wire was placed in the middle of the survey area along a straight road. The source signal was a square waveform current of $20 \mathrm{~A}$ with $50 \%$ duty cycle at $12.5 \mathrm{~Hz}$. Due to the UAV duration capacity, there are less than 9 lines can be covered in each flight. The flight path was showed in Fig.3 which looks like a clip. To verify the inversion result, we compared a piece of data to a borehole, which is showed at the arrow point in Fig.3. The inversion result showed in Fig. 4 is plotted by a pseudo-color map. The black dash line is the borehole location, and the borehole data is showed in the right of Fig. 4.

There are 4 resistivity layers at the borehole location from surface to the deep in resistivity profile. The resistivity of the first layer is about $300 \sim 500 \Omega \mathrm{m}$, and the depth is from surface to $30 \mathrm{~m}$ underground, corresponding to the perched sediment and gravel bed layers of the borehole data. The perched sediment and gravel bed has the similar resistivity due to the influence of surface weathering and precipitation. The resistivity of the second layer is about $1000 \sim 2000 \Omega \mathrm{m}$, and the depth is from $30 \mathrm{~m}$ to $150 \mathrm{~m}$ underground, corresponding to the oxidized pedestal rock and limestone layers of the borehole data with resistivity difference is not obviously. The resistivity is about $300 \sim 500 \Omega \mathrm{m}$ in the middle and $500 \sim 800 \Omega \mathrm{m}$ at the border of the third layer. There are two reasons under this circumstance, one is the gradually varied at the contacted region of the two lithology layers, the other is the occam's inversion based on a smooth model. The depth is from $150 \mathrm{~m}$ to $300 \mathrm{~m}$ underground, corresponding to the granite layer with strong pyritization. The last layer corresponding to the sandstone layer of the borehole data, the pressure make the sandstone hard and density, showing a high resistivity more than $2000 \Omega \mathrm{m}$.

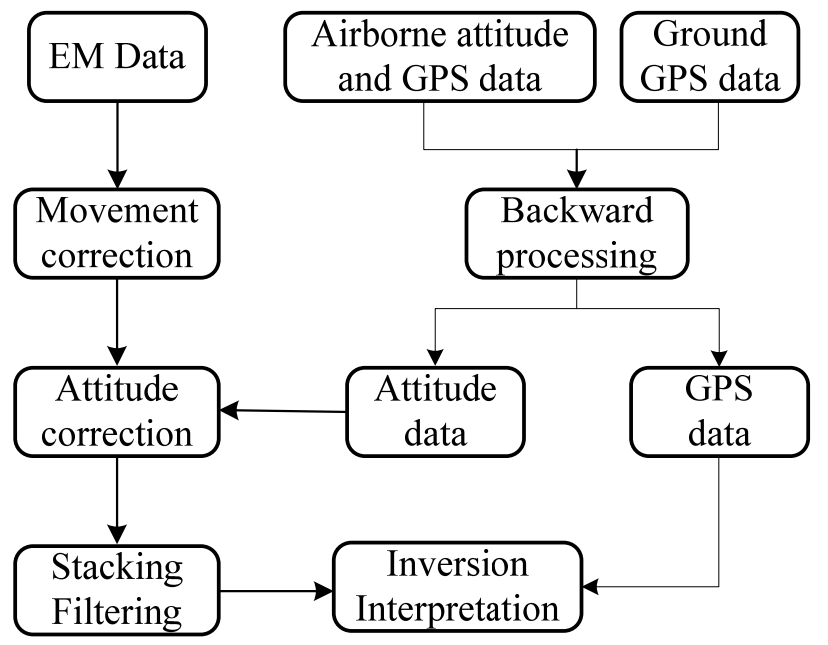

Fig. 2. Data processing flow chart of S-ATEM system

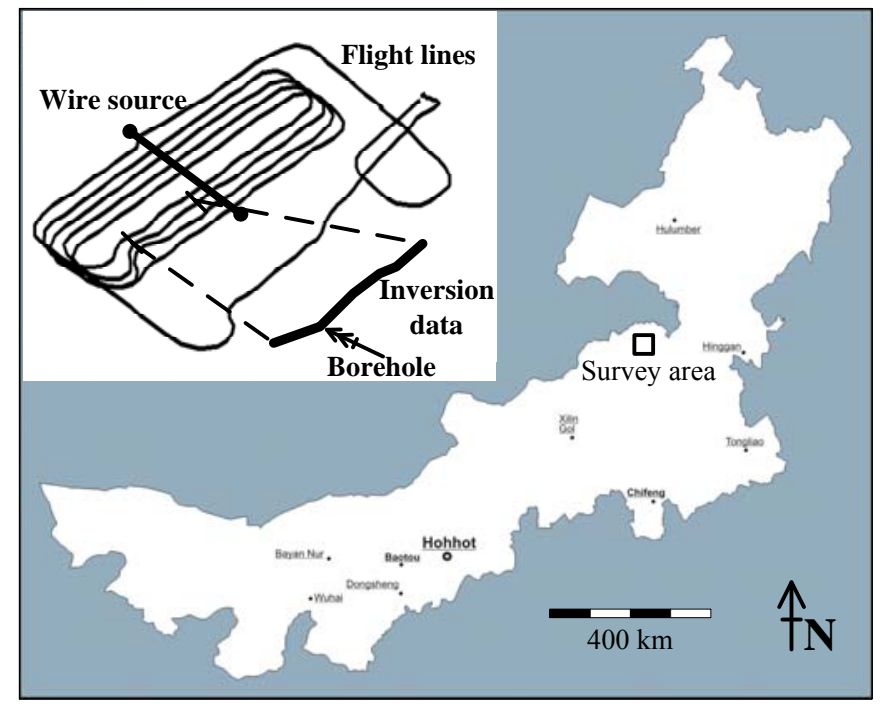

Fig. 3. Survey site location and flight information

As comparing the inversion profile to the borehole lithology, the inversion result and borehole data fit well with each other, the resistivity anomy and the layer segmentation mostly accords with the borehole data, and it proves that the SATEM system can successfully and effectively detected underground resistivity distribution of subsurface.

\section{CONCLUSION}

we introduced a new S-ATEM system based on UAV, including system configuration and data processing method. A testing survey was also carried out to validate the applicability of the S-ATEM. The testing survey result demonstrates that the S-ATEM system has an investigation depth more than $400 \mathrm{~m}$, and the advantages of lower cost, portable , higher efficiency, and more safety compared with the traditional EM system. 


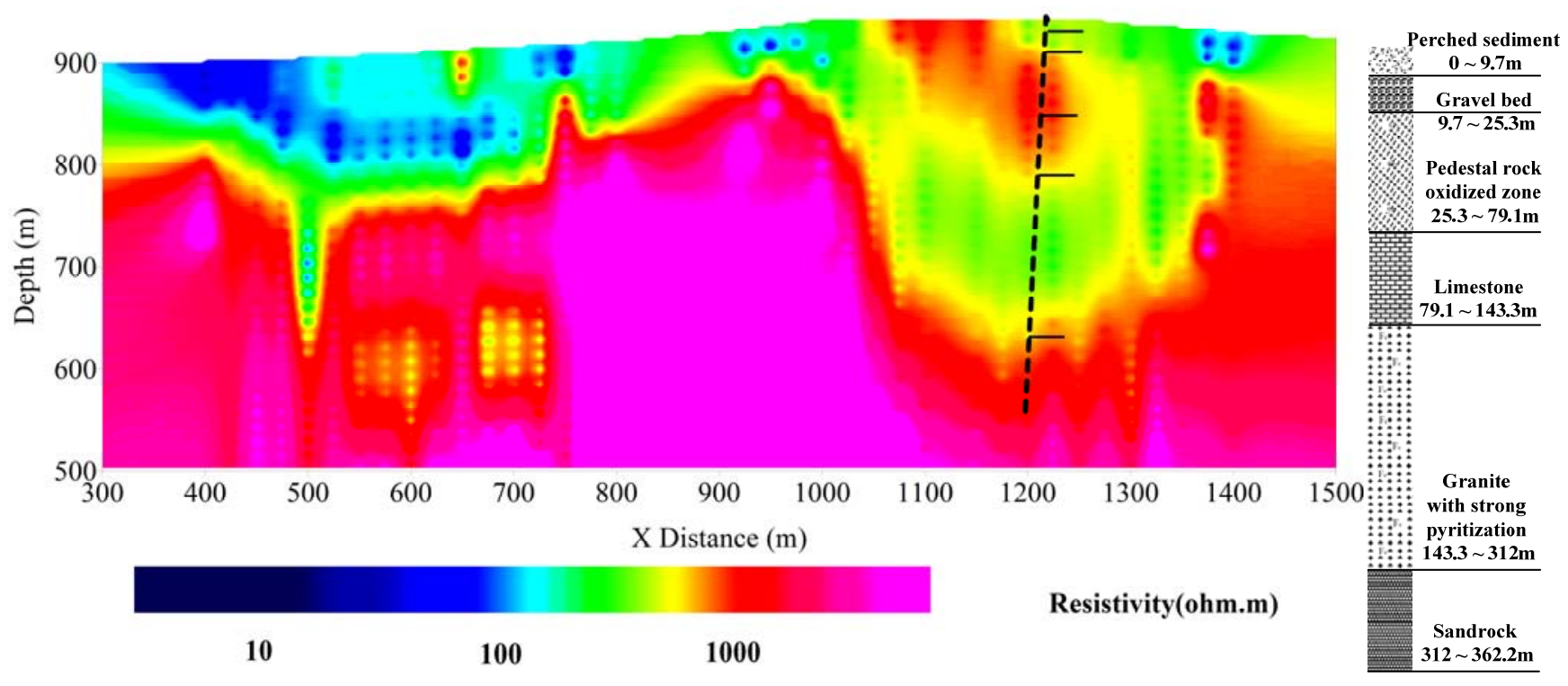

Fig. 4. Inversion profile and comparing to borehole lithology layer

\section{ACKNOWLEDGMENT}

This study is supported by R\&D of Key Instruments and Technologies for Deep Resources Prospecting (the National R\&D Projects for Key Scientific Instruments), Grant No.ZDYZ2012-1-03-05 ATEM flight test, data process and interpretation software technology.

\section{REFERENCES}

[1] P. Elliott, "New airborne electromagnetic method provides fast deeptarget data turnaround," The leading edge, vol. 4, pp. 309-310, 1996.

[2] P. Elliott, "The principles and practice of FLAIRTEM," Exploration Geophysics. vol. 29(2), pp. 58-60, 1998.

[3] T. mogi, Y. Tanaka, K. Kusunoki, T. Morikawa, and N. Jomori, "Development of grounded electrical source airborne transient EM(GREATEM)," Exploration Geophysics. vol. 29, pp. 61-64, 1998.

[4] T. Mogi, K. Kusunoki, H. Kaieda, H. Ito, A.Jomori, N. Jomori, and Y. Yuuki, "Grounded electrical-source airborne transient electromagnetic (GREATEM) survey of Mount Bandai, north-eastern Japan," Exploration Geophysics. vol. 40, pp. 1-7, 2009.
[5] H. Ito, T. Mogi, A.Jomori, Y. Yuuki, K. Kiho, H. Kaieda, K. Suzuki, K. Tsukuda, and S. A. Allah, "Further investigations of underground resistivity structures in coastal areas using grounded-source airborne electromagnetic," Earth Planets Space, vol. 63, pp. 9-12, 2011.

[6] K. Okazaki, T. Mogi, M. Utsugi, Y. Ito, H. Kunishima, T. Yamazaki, Y.Takahashi, T. Hashimoto, Y. Ymamaya, H. Ito, H. Kaieda, K. Tsukuda, Y. Yuuki, and A. Jomori, "Airborne electromagnetic and magnetic surveys for long tunnel construction design," Physics and Chemistry of the Earth, vol. 36, pp. 1237-1246, 2011.

[7] S. A. Allah, T. Mogi, H. Ito, A. Jomori, Y. Yuuki, E. Fomenko, K. Kiho, H. Kaieda, K. Suzuki, and K. Tsukuda, "Three-dimensional resistivity characterization of a coastal area: Application of Grounded ElectricalSource Airborne Transient Electromagnetic (GREATEM) survey data from Kujukuri Beach, Japan," Journal of Applied Geophysics, vol. 99, pp. 1-11, 2013.

[8] H. Ito, H. Kaieda, T. Mogi, A. Jomori, and Y. Yuuki, "Grounded electrical-source airborne transient electromagnetics (GREATEM) survey of Aso Volcano," Exploration Geophysics.

[9] R. S. Smith, A. P. Annan, and P. D. McGowan, "A comparison of data from airborne, semi-airborne, and ground electromagnetic systems," Geophysics, vol. 66(5), pp. 1379-1385, 2001. 